\title{
Comparative Analysis for the Surgical Outcomes of Uvulopalatal Flap and Palatal Muscle Resection in Patients with Obstructive Sleep Apnea
}

\author{
Hyun-Min Lee, Sung-Won Choi, Dae-Woon Kang, \\ Jung-Hoon Lee, Hwan-Jung Roh and Kyu-Sup Cho \\ Department of Otorhinolaryngology-Head and Neck Surgery, Pusan National University School of Medicine, Busan, Korea
}

\author{
폐쇄성 수면무호흡증 환자에서 구개수구개피판술과 구개근절제술의 수술 결과에 대한 비교 분석 \\ 이현민 · 최성원 · 강대운 - 이정훈 · 노환중 · 조규섭 \\ 부산대학교 의학전문대학원 이비인후과학교실
}

\author{
Received March 24, 2011 \\ Revised June 2, 2011 \\ Accepted June 14, 2011 \\ Address for correspondence \\ Kyu-Sup Cho, MD \\ Department of Otorhinolaryngology- \\ Head and Neck Surgery, \\ Pusan National University \\ School of Medicine, \\ 305 Gudeok-ro, Seo-gu, \\ Busan 602-739, Korea \\ Tel $+82-51-240-7824$ \\ Fax $+82-51-246-8668$ \\ E-mail choks@pusan.ac.kr
}

Background and Objectives The purpose of this study was to compare the surgical outcomes of uvulopalatal flap (UPF) and palatal muscle resection (PMR) techniques in the treatment of obstructive sleep apnea (OSA).

Subjects and Method Forty-three consecutive patients ( 40 men and 3 women) with OSA were included. Only patients with Fujita type I obstruction were enrolled in this study. Patients with macroglossia or retrognathia were excluded from the study. Twenty patients underwent a UPF and twenty-three patients underwent a PMR. In both groups, nasal surgery was performed if necessary. Questionnaires based on Visual Analogue Scale (VAS) about snoring, apnea, morning headache, tiredness, daytime sleepiness and Epworth Sleepiness Scale (ESS) were analyzed before and after each surgical treatment. Preoperative and postoperative polysomnography (PSG) were completed by every patient.

Results In UPF group, every aspect of VAS except morning headache was significantly improved after surgery. In PMR group, every aspect of VAS and ESS were significantly improved after surgery. Comparing the surgical outcomes between two groups, every VAS and ESS showed much better result in PMR than UPF group. In both UPF and PMR group, the mean apnea-hypopnea index decreased significantly after surgery. However, there's no significant difference between two groups in the PSG findings.

Conclusion PMR could be a better surgical technique than UPF with respect to subjective outcome although both UPF and PMR are effective surgical techniques for the treatment of OSA with Fujita type I obstruction.

Korean J Otorhinolaryngol-Head Neck Surg 2011;54:467-72

Key Words Obstructive sleep apnea $\cdot$ Soft palate $\cdot$ Operative surgical procedures.

\section{서 론}

코골이나 폐쇄성 수면무호흡증의 수술적 치료는 폐쇄 부위 를 넓혀주거나 인두 근육의 긴장도를 높여주는 것이 치료의 원칙이다. 구인두 수술은 구인두 부위의 폐쇄가 있는 환자에 서 해부학적으로 좁아져 있는 상기도의 공간을 넓히거나 연
구개 근육의 긴장도를 높이기 위하여 시도되고 있다. ${ }^{1)}$ Fujita 등 $^{2}$ 이 소개한 구개수구개인두성형술(uvulopalatopharyngoplasty, UPPP)은 가장 많이 시행된 수술이지만 수술 성공률 이 예상보다 만족스럽지 않으며, 수술에 따른 구개인두부전, 비인두 협착, 구인두 건조 및 이물감 등 부작용이 보고되고 있 다. ${ }^{3,4)}$ 이에 많은 연구자들이 수술 결과를 향상시키고 부작용 
을 감소시키기 위해 전통적인 UPPP의 변형된 여러 가지 방법 을 제시하였으며 ${ }^{1,5,6,7)}$ 그 중에서 Powell 등')이 제안한 구개수 구개피판술(uvulopalatal flap, UPF)은 여러 연구자들에 의 하여 안전하고 효과적인 방법이라 보고되었다. ${ }^{89)} \mathrm{Kim}$ 드이은 연구개를 거상시키는 데 관여하는 구개근을 절제한 후 단단문 합하는 구개근절제술(palatal muscle resection, PMR)이 UP$\mathrm{PP}$ 에 비하여 연구개 및 주변 조직의 제거가 적고 구개수를 보 존할 수가 있어 통증이나 인두 이물감이 적은 효과적인 치료 라고 하였다.

이에 저자들은 코골이와 중등도 이상의 폐쇄성 수면무호흡 증이 있는 환자들을 대상으로 UPF와 PMR을 시행한 후 수술 방법에 따른 주관적 증상변화의 정도와 객관적 수면다원검 사를 통한 결과를 비교 분석하고자 하였다.

\section{대상 및 방법}

\section{대 상}

2008년 6월부터 2009년 12월까지 코골이 및 수면무호흡증 으로 수술적 치료를 시행 받은 환자는 총 76 명이었다. 이 중 에서 60명이 6개월 이상 추적 관찰이 가능하였으며 그 중 중 등도 이상의 수면무호흡증을 가지고 있고 주된 폐쇄부위가 구인두 부위인 환자는 53명이었으며 이 중 수술 후 수면다원 검사를 시행한 43명의 환자를 대상으로 하였다. 수술 전에 수 면다원검사(Embla S7000, Embla System, USA)를 시행하 여 중등도 이상의 수면무호흡증을 가진 환자들 중 굴곡형 비 인두경 검사를 통한 Muller법, Friedman 병기 분류, 측면 두 개골 계측 촬영 등을 통해 기도폐쇄 부위를 확인하여 설근 부를 포함한 하인두의 폐쇄가 있는 환자는 대상에서 제외하 였다.

20명은 UPF를 시행하였으며, 23명은 PMR을 시행하였다. 이학적 검사에서 연구개가 길고 많이 늘어진 환자는 주로 P$\mathrm{MR}$ 을, 후구개궁(posterior pillar)이 과다하여 구인두 측벽이 좁은 환자에서는 주로 UPF을 시행하였으며, UPF군에서 7명, $\mathrm{PMR}$ 군에서 6명은 비폐색이 있어 수술시 비중격 교정술을 같이 시행하였다. 연령 분포에서 UPF군은 19 세에서 65 세로 평균 37.9세였으며, PMR군은 21세에서 65세로 평균 36.8세 였다. 성별 분포는 UPF군은 모두 남자였으며, PMR군은 남자 20 명, 여자 3 명이었다. 평균 체질량지수(body mass index,

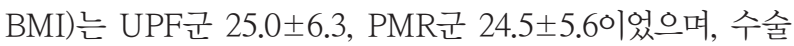
전 평균 무호흡-저호흡지수(apnea-hypopnea index, AHI)는

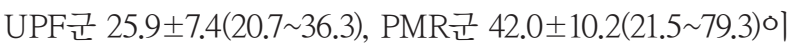
었다.

\section{수술방법}

모든 환자에서 편도가 큰 경우는 편도절제술을 시행한 후 $\mathrm{UPF}$ 는 Powell 등')이 보고한 방법과 같이 구개수가 긴 경우 는 구개수를 부분적으로 자른 후 당겼을 때 연구개에 중첩되 는 점막만을 절개하여 제거한 후 구개수 피판을 앞으로 당겨 경 - 연구개 접합부에 vicryl 3 0로 매달아 고정하였다. 구인두 측벽이 좁은 경우는 $\mathrm{Li}$ 등이이 제안한 확장 UPF 방법으로 편 도와의 상부에서 하악의 대구치를 향해 약 $1 \mathrm{~cm}$ 정도 삼각형 의 절개를 가한 후 점막과 점막하 지방조직을 제거하여 구인 두 측벽을 더 확장하였다. PMR은 $\mathrm{Kim}$ 등이 이 소개한 방법대 로 위쪽 경계는 연구개의 dimpling point에서 $0.5 \mathrm{~cm}$ 아래쪽, 아래쪽 경계는 구개수의 기저부, 좌·우측 경계는 편도의 앞 쪽 지주(anterior pillar of tonsil)의 연장선으로 정하고 단극 성 전기소작기(monopolar electrocautery)로 연구개의 점막 과 구개수근(uvular muscle), 구개거근(levator veli palatini muscle), 구개설근(plalatoglossus muscle)의 일부를 포함하여 타원형으로 제거한 후 vicryl 2 0로 근육을 봉합한 후 black silk 2 0로 절제된 점막의 변연을 단순 봉합하였다.

\section{평가방법}

주관적 증상의 개선 정도는 모든 환자에서 수술 전과 수술 후 6 개월에 동일한 내용의 설문을 시행하였다. 설문은 환자 또는 환자와 같이 생활하는 보호자를 대상으로 직접 면접 또 는 전화 설문 방식으로 시행되었다. 설문은 체중, 키를 조사하 고 코골이, 수면 중 무호흡 정도, 조조두통, 피로, 주간 졸림 5 항목에 대해서 증상점수(visual analogue scale, VAS)를 조 사하였고, Epworth Sleepiness Scale(ESS)을 같이 시행하여 비교하였다. VAS는 0 10점까지, ESS는 0 24점까지 점수를 측정하였으며, 점수가 높을수록 환자가 호소하는 증상이 심 한 것을 의미한다. 그리고 수술 후 환자가 불편해하는 구인두 건조 및 이물감, 비강내로 음식의 역류 등에 대한 설문을 시 행하였다.

수면다원검사는 모든 환자에서 수술 전과 수술 후 6 개월에 시행 하였다. 수면다원검사를 통하여 무호흡-저호흡지수, 수 면 중 평균 산소 포화도와 최소 산소 포화도를 측정하였고 각 군에서 수술 전·후를 비교하였다.

\section{통계분석}

모든 통계처리는 SPSS 18(IBM corporation, Somers, NY, USA)을 이용하여 수술 전·후 비교는 Wilcoxon signed rank test로, UPF와 PMR 양 군간의 비교는 Mann-Whitney U test 를 사용하였으며, $p$-value가 0.05 보다 작은 경우를 의미 있는 것으로 판정하였다. 


\section{결 과}

$\mathrm{UPF}$ 와 PMR 양 군 간에 연령, 수술 전·후 체질량지수, 수 술 전 무호흡-저호흡지수, Friedman 병기 분류에서 모두 의 미 있는 차이는 없었다(Table 1).

주관적 증상의 개선 정도는 $\mathrm{UPF}$ 군의 경우 $\mathrm{VAS}$ 중 코골이, 수면 중 무호흡 정도, 피로, 주간 졸림의 정도가 수술 전에 비 하여 유의하게 호전되었고, 조조두통에 대한 VAS와 ESS는 유의한 차이를 보이지 않았다. PMR을 시행한 군에서는 코골

Table 1. Patient characteristics of the study groups

\begin{tabular}{lccc}
\hline & UPF $(\mathrm{n}=20)$ & $\mathrm{PMR}(\mathrm{n}=23)$ & $\mathrm{P}$ \\
\hline Age & $37.9 \pm 9.9$ & $36.8 \pm 8.7$ & 0.765 \\
Preop BMI & $25.0 \pm 3.6$ & $24.5 \pm 3.1$ & 0.638 \\
Postop BMI & $25.3 \pm 2.9$ & $24.6 \pm 2.6$ & 0.543 \\
Preop AHI & $25.9 \pm 6.4$ & $42.0 \pm 9.7$ & 0.091 \\
Postop AHI & $10.6 \pm 5.7$ & $5.6 \pm 7.6$ & 0.167 \\
Friedman classification & & & \\
Tongue position (no.) & & & \\
$\quad 1$ & 5 & 4 & 0.467 \\
2 & 12 & 14 & \\
3 & 3 & 5 & \\
Tonsil size (no.) & & & \\
1 & 2 & 4 & 0.877 \\
2 & 8 & 6 & \\
3 & 10 & 13 & \\
\hline
\end{tabular}

UPF: uvulopalatal flap, PMR: palatal muscle resection, Preop: Preoprative data, Postop: Postoperative data, BMl: body mass index, AHI: apnea-hypnea index, p: p-value
이, 수면 중 무호흡 정도, 조조두통, 피로, 주간 졸림에 대한 V$\mathrm{AS}$ 가 모두 감소하였고 $\mathrm{ESS}$ 도 유의한 감소를 보였다(Table 2).

수술 전과 후에 시행한 수면다원검사에서 $\mathrm{AHI}$ 는 UPF군 에서는 술 전 25.9에서 술 후 10.6으로 PMR군에서는 술 전 42.0에서 술 후 5.6으로 UPF군과 PMR군 모두에서 수술 전 에 비해 AHI가 유의하게 감소하였다. 하지만 수면 중 최소 산 소포화도, 수면 중 평균 산소 포화도는 둘 다 수술 이후에 증 가하였으나 두 군 모두에서 유의한 차이는 없었다(Table 3).

$\mathrm{UPF}$ 와 PMR 양군 간에 수술 전·후의 주관적 증상의 개 선 정도와 수면다원검사를 비교해 볼 때 환자가 느끼는 주관 적 증상은 $\mathrm{VAS}$ 와 $\mathrm{ESS}$ 모두에서 $\mathrm{UPF}$ 군에 비해 $\mathrm{PMR}$ 군에서 의미 있는 호전을 보여주었다(Fig. 1). 수면다원검사에서 수술 전·후의 AHI는 PMR군에서 더 많이 감소하였으나 양군 간 에 유의한 차이는 없었으며, 수면 중 최소 산소포화도, 수면 중 평균 산소 포화도도 양군 간에 유의한 차이는 없었다(Fig. 2).

수술 후 환자가 불편해 하는 증상은 UPF군의 경우 역류증 상이 1명, 이물감이 1 명, 구강 건조가 1명이었으며, PMR군은 역류증상 1 명, 이물감이 1 명, 구강건조가 2 명 있었으나 양군 간에 특별한 차이를 보이지 않았다.

\section{고 찰}

폐쇄성 수면무호흡증의 수술적 치료는 기능 이상의 인두구 조를 변경하거나 폐쇄부위를 개선하는 것이다. 수면 중 상기 도의 폐쇄는 한두 부위에 국한될 수도 있지만 비강, 구인두,

Table 2. Comparisons of preoperative and postoperative BMI, VAS and ESS in each surgical groups

\begin{tabular}{|c|c|c|c|c|c|c|}
\hline & & UPF & & & PMR & \\
\hline & Preop & Postop & $p$ & Preop & Postop & $p$ \\
\hline $\mathrm{BMI}$ & 25.0 & 25.3 & 0.457 & 24.5 & 24.6 & 0.835 \\
\hline VAS & & & & & & \\
\hline Snoring & 8.0 & 5.9 & 0.000 & 8.4 & 4.0 & $<0.001$ \\
\hline Sleep apnea & 6.7 & 4.0 & 0.000 & 7.1 & 2.0 & $<0.001$ \\
\hline Morning headache & 1.5 & 1.8 & 0.250 & 3.3 & 1.2 & 0.002 \\
\hline Tiredness & 5.1 & 4.1 & 0.038 & 5.5 & 2.3 & $<0.001$ \\
\hline Daytime sleepiness & 4.5 & 3.4 & 0.031 & 4.9 & 2.1 & 0.001 \\
\hline ESS & 8.4 & 7.7 & 0.344 & 11.8 & 6.9 & $<0.001$ \\
\hline
\end{tabular}

BMI: body mass index, VAS: visual analogue scale, ESS: Epworth Sleepiness Scale, UPF: uvulopalatal flap, PMR: palatal muscle resection, Preop: Preoprative data, Postop: Postoperative data, $p: p$-value

Table 3. Comparisons of preoperative and postoperative PSG findings in each surgical groups

\begin{tabular}{|c|c|c|c|c|c|c|}
\hline \multirow{2}{*}{ PSG } & \multicolumn{3}{|c|}{ UPF } & \multicolumn{3}{|c|}{ PMR } \\
\hline & Preop & Postop & $p$ & Preop & Postop & $p$ \\
\hline $\mathrm{AHI}$ & 25.9 & 10.6 & 0.004 & 42.0 & 5.6 & 0.001 \\
\hline ASAT & 94.0 & 95.8 & 0.125 & 95.7 & 95.9 & 0.982 \\
\hline LSAT & 74.8 & 87.3 & 0.125 & 83.2 & 88.3 & 0.098 \\
\hline
\end{tabular}

PSG: polysomnography, UPF: uvulopalatal flap, PMR: palatal muscle resection, Preop: Preoperative data, Postop: Postoperative data, p: p-value, AHI: apnea-hypnea index, ASAT: average oxygen saturation, LSAT: Lowest oxygen saturation 


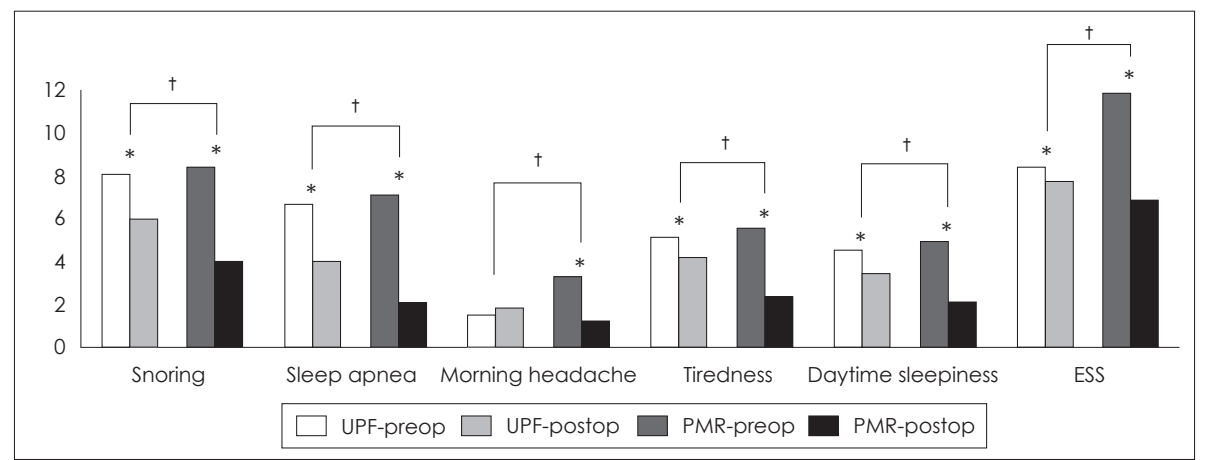

Fig. 1. Preoperative and postoperative comparative analysis of VAS and ESS between UPF and PMR group. *significant difference between preoperative and postopearative values. $p<0.05$. †significant difference between results of two surgical methods. $p<0.05$. VAS: visual analogue scale, ESS: Epworth Sleepiness Scale, UPF: uvulopalatal flap, PMR: palatal muscle resection, UPF-preop: preoperative value of UPF group, UPF-postop: postoperative value of UPF group, PMR-preop: preoperative value of UPF group, PMR-postop: postoperative value of PMR group.

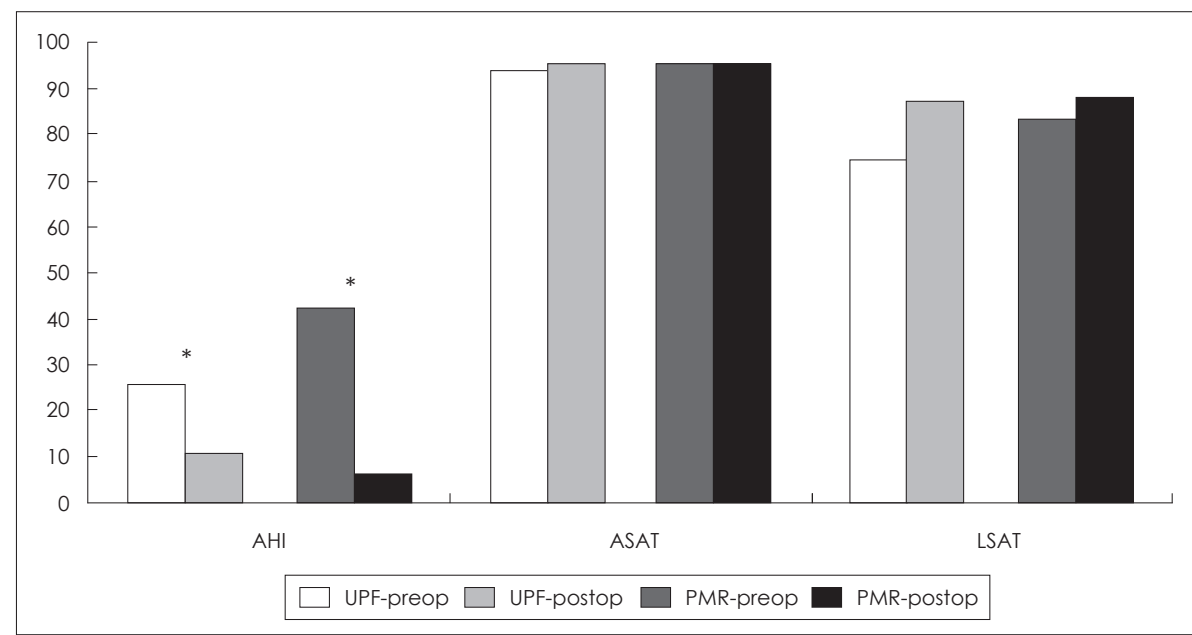

Fig. 2. Preoperative and postoperative comparative analysis of PSG findings between UPF and PMR group. *significant difference between preoperative and postopearative values. $p<0.05$. PSG: Polysomnography, UPF: Uvulopalatal flap, PMR: palatal muscle resection, UPF-preop: preoperative value of UPF group, UPF-postop: postoperative value of UPF group, PMR-preop: preoperative value of UPF group, PMR-postop: postoperative value of PMR group, AHI: apnea-hypnea index, ASAT: average oxygen saturation, LSAT: Lowest oxygen saturation.

하인두의 모든 상기도에 발생할 수도 있다. 그러므로 수술의 계획에서 가장 중요한 것은 폐쇄 부위의 확인과 적절한 수술 방법의 선택이다. 폐쇄성 수면무호흡증 환자에서 구개와 측인 두벽 부위의 폐쇄가 중요하다는 것은 이미 알려져 있지만 수 술 방법과 수술 후의 결과는 다양하다. 많은 구인두 수술 방 법들이 구인두 부위의 폐쇄는 분명히 해결했음에도 불구하고 실패를 하는 주된 이유는 인식하지 못한 설근부(하인두)의 문 제 때문이다. 폐쇄의 가장 중요한 부위가 구인두 부위일 경우 는 수술 성공률이 80 90\%가 되지만 그 외의 부위일 경우는 5 30\%까지 떨어질 수도 있으므로 ${ }^{10}$ 상기도에서 정확한 폐쇄 부위를 확인하는 것이 무엇보다 중요하다. 본 연구에서는 이 학적 검사, 비인두 내시경 검사, 두개골 계측 촬영 등을 종합 분석하여 상기도의 폐쇄 부위를 확인한 후 설근부를 포함한 하인두의 폐쇄가 있는 환자는 제외하고 구인두의 폐쇄만 있 는 환자를 대상으로 하였다.
구인두 수술은 과도한 양의 연구개 조직, 낮게 내려앉은 연 구개, 편도 비후, 구개수 비대, 심한 인두점막추벽 등이 있는 환 자에게 시행할 수 있으며 이 부위에 대해서는 많은 수술 방법 들이 소개되어 있다. 1981년 Fujita 등레 에하여 UPPP가 보 급된 이후로 많은 술자들에 의하여 그 수술적 효과가 기대에 못 미치고 영구적인 합병증의 발생이 문제가 됨을 알게 되면 서 보다 효과적인 UPPP의 변형된 여러 가지 방법이 개발되었 다. 일부는 광범위한 절제를 통하여 기도를 넓혀주기 위한 방 향으로, 또 다른 일부는 보존적이면서도 반흔 형성의 발생을 줄이려는 방향으로 이러한 노력은 이루어졌다. 본 연구에서 사용된 UPF는 1996년 Powell 등이 보고한 후 단·장기간의 경과관찰을 한 여러 연구에서 술 후 결과는 UPPP와 차이가 없으면서 환자가 호소하는 통증이나 합병증은 UPPP에 비해 의미 있게 적었다고 하였다. ${ }^{899} \mathrm{PMR}$ 은 구개근의 단단문합을 중심으로 한 술식으로 UPPP 등에 비하여 연구개 및 주변 조 
직의 제거가 적고 구개수를 보존할 수 있다고 하였다. ${ }^{1)}$

이에 본 연구는 과도한 조직의 절제로 인한 UPPP의 문제 점을 극복하기 위해 시행되고 있는 UPPP의 변형된 여러 가 지 방법 중 흔히 사용되는 UPF와 PMR의 수술 방법에 따른 결과를 비교분석하고자 하였다. 각각의 수술 방법을 통한 치 료의 결과는 주관적인 증상의 호전 정도와 객관적인 수면다 원검사를 이용하여 판단하였다. 주관적인 증상에 대한 $\mathrm{VAS}$ 와 $\mathrm{ESS}$ 의 결과를 비교해 볼 때 PMR군에서는 코골이, 수면 중 무호흡 정도, 조조두통, 피로, 주간 졸림에 대한 VAS 모두 가 통계적으로 유의한 호전을 보였으며 ESS 또한 통계적으로 유의한 호전을 보였지만 UPF군에서는 조조두통에 대한 VAS 와 ESS는 유의한 차이를 보이지 않았다. 수술 전·후의 수면 다원검사를 비교해 보면 UPF와 PMR군 모두에서 무호흡-저 호흡지수가 의미 있게 감소하였다. 본 연구에서 UPF군은 7 명, PMR군은 6명에서 비폐색이 있어 수술시 비중격 교정술 을 같이 시행하였는데 UPF와 PMR만 시행한 경우와 비중격 교정술을 같이 시행한 군을 따로 비교해 보아도 주관적 증상 과 수면다원검사 모두에서 동일한 결과를 보였다.

수술의 성공에 대한 기준을 $\mathrm{AHI}$ 가 $50 \%$ 이상 감소하고 $\mathrm{AHI}$ 가 20 이하인 경우로 정의할 때 ${ }^{11,12)}$ 본 연구의 모든 환자에서 수술은 성공하였다. 이는 본 연구가 후향적 연구였기 때문에 수술 후 증상이 호전되고 추적 관찰이 잘 되는 환자만 연구 에 포함되었을 가능성이 많을 것으로 생각되며 또한 수술 전 여러 가지 검사를 통하여 설근부를 포함한 하인두의 폐쇄가 있는 환자는 제외하고 구인두의 폐쇄만 있는 환자를 대상으 로 하였기 때문으로 생각된다. 물론 본 연구에서 시행한 상기 도의 폐쇄 부위를 확인하기 위한 검사들은 모두 실제 수면 상 태의 검사가 아니므로 수면시와는 다를 수 있고 각성시에 하 인두의 폐쇄가 없는 환자가 수면 중에도 폐쇄가 없다고 할 수 없다는 것은 본 연구의 제한점이라고 할 수 있다.

$\mathrm{UPF}$ 와 PMR 두 가지 수술 방법을 비교 분석해 볼 때 수면 다원검사에서는 특별한 차이를 보이지 않았지만 주관적 증 상의 개선 정도는 모든 $\mathrm{VAS}$ 와 $\mathrm{ESS}$ 에서 통계적으로 유의하게 $\mathrm{PMR}$ 군에서 높은 것을 알 수 있었다. 수술의 성공 여부를 판 단할 때 수면다원검사에 의한 객관적인 호전도 중요하지만 코 골이를 포함한 주관적인 증상의 호전도 중요한 점을 생각해 볼 때 PMR은 UPF에 비해 효과적인 치료방법이 될 수 있을 것으로 생각된다.

$\mathrm{PMR}$ 은 UPPP에 비하여 연구개 및 주변조직의 제거가 작 고 구개수를 보존할 수 있으며 수술 후 형성되는 반흔이 연구 개의 구개면에 생기므로 연구개를 앞쪽 위쪽으로 당겨 구개 후방 부위가 넓어지는 것으로 생각된다. ${ }^{1)}$ 구개수는 발성시 조 음에 기여하고 구강의 습기를 유지시키는 데 있어 중요한 역할
을 하며, ${ }^{13)}$ 구개수에 연구개 조직에 비하여 장액성 분비물을 분비하는 타액선이 더 많아 구강 내의 가습에 중요하다고 하 였다. ${ }^{14)}$ 이러한 면에서 UPPP 이후의 구강 내 건조감과 이물 감은 구개수를 보존하지 못한데서 기인한다고 생각되며 실제 로 UPPP에서 구개수를 보존한 군에서 반흔 형성과 인두이물 감을 호소하는 빈도가 줄었다는 보고도 있었다.,7) 하지만 PMR 을 시행한 경우에서도 봉합사에 의한 이물감을 호소하는 환 자가 보고되었고, ${ }^{1)}$ 본 연구에서도 통계적으로 조사되지는 않 았지만 수술 이후에 일시적인 역류현상이나 이물감, 구강건조 가 있다는 환자가 있어 이는 향후 더욱 많은 연구가 있어야 할 것으로 생각된다.

결론적으로 UPF와 PMR 모두 구인두의 폐쇄를 동반한 중 등도 이상의 폐쇄성 수면무호흡환자에게 UPPP를 대체할 수 있는 효과적인 구인두의 수술 방법으로 생각되지만 코골이를 포함한 주관적 증상의 호전에 대한 관점에서 볼 때 PMR이 $\mathrm{UPF}$ 에 비해 좀 더 효과적인 구인두 부위의 수술이 될 수 있 을 것으로 생각된다.

\section{Acknowledgments}

This work was supported by clinical research grant from Pusan National University Hospital 2011.

\section{REFERENCES}

1) Kim TH, Koo SK, Han CW, Kim YC, Ahn GY. Palatal muscle resection (PMR) for the treatment of snoring patients. Korean J Otorhinolaryngol-Head Neck Surg 2008;51(12):1119-23.

2) Fujita S, Conway W, Zorick F, Roth T. Surgical correction of anatomic azbnormalities in obstructive sleep apnea syndrome: uvulopalatopharyngoplasty. Otolaryngol Head Neck Surg 1981;89(6):923-34.

3) Cho SH, Lee KY, Chung JH, Kim BS, Jeong JH, Kim KR. Minimally Invasive Surgical Technique in Uvulopalatopharyngoplasty: Palatoglossal Line. Korean J Otolaryngol-Head Neck Surg 2007;50(5): 411-5.

4) Lysdahl M, Haraldsson PO. Uvulopalatopharyngoplasty versus laser uvulopalatoplasty: prospective long-term follow-up of self-reported symptoms. Acta Otolaryngol 2002;122(7):752-7.

5) Lee SH, Wang SG, Koo SK, Koo HE, Yun JH, Roh HJ, et al. Longterm polysomnographic findings and subjective results in sleep apnea patients treated with laser assisted uvulopalatoplasty. Korean J Otolaryngol-Head Neck Surg 2002;45(2):144-8.

6) Powell N, Riley R, Guilleminault C, Troell R. A reversible uvulopalatal flap for snoring and sleep apnea syndrome. Sleep 1996;19(7): 593-9.

7) Shin SH, Ye MK, Kim CG. Modified uvulopalatopharyngoplasty for the treatment of obstructive sleep apnea-hypopnea syndrome: resection of the musculus uvulae. Otolaryngol Head Neck Surg 2009;140 (6):924-9.

8) Neruntarat C. Uvulopalatal flap for obstructive sleep apnea: shortterm and long-term results. Laryngoscope 2011;121(3):683-7.

9) Li HY, Li KK, Chen NH, Wang PC. Modified uvulopalatopharyngoplasty: The extended uvulopalatal flap. Am J Otolaryngol 2003;24 (5):311-6.

10) Friedman M, Ibrahim H, Bass L. Clinical staging for sleep-disordered breathing. Otolaryngol Head Neck Surg 2002;127(1):13-21.

11) Won CH, Li KK, Guilleminault C. Surgical treatment of obstructive 
sleep apnea: upper airway and maxillomandibular surgery. Proc Am Thorac Soc 2008;5(2):193-9.

12) Mickelson SA, Ahuja A. Short-term objective and long-term subjective results of laser-assisted uvulopalatoplasty for obstructive sleep apnea. Laryngoscope 1999;109(3):362-7.
13) Olofsson K, Mattsson C, Hammarström ML, Hellström S. Structure of the human uvula. Acta Otolaryngol 1999;119(6):712-7.

14) Balcerzak J, Górnicka B, Karchier E. [What should we know about uvula doing uvulopalatoplasty]. Otolaryngol Pol 2006;60(6):879-82. 